\title{
EXTRANJEROS EN ESPAÑA EN 1991
}

\author{
POR \\ GLORIA LORA-TAMAYO D'OCON
}

\section{Introducción}

El año 1991 es clave en la investigación de la inmigración extranjera en España, por la concurrencia de dos fuentes de primera magnitud: un Censo de Población y los informes estadísticos de la regularización de extranjeros llevada a cabo ese mismo año.

El Censo de Población tiene como fecha de referencia el 1 de marzo de 1991. No es un registro obligatorio, por lo que parece lógico pensar que gran parte, si no la mayoría, de los extranjeros en situación irregular, no se inscribieran, dado su temor a aparecer en cualquier tipo de registro, sintiéndose «más seguros cuanto más sumergidos se hallen» (R. Aragón y J. Chozas, 1993).

Por su parte, a la Regularización acudieron los extranjeros que se encontraban en situación irregular, insuficientemente documentados, a quienes comúnmente se alude con el término de «ilegales». Su volumen sólo se conocía por estimaciones y su perfil se adivinaba a través de los que acudían a instituciones y Ong's en busca de ayuda. Condición imprescindible, entre otras, para acudir al proceso era el hallarse en España con anterioridad al 15 de mayo de 1991.

Aunque la cifra real de extranjeros residiendo en nuestro país en 1991 no puede simplificarse a la suma de ambos bloques -los mayo-

Estudios Geográficos

Tomo LVII, n. ${ }^{\circ}$ 222, enero-marzo 1996 
ritariamente regulares del Censo y los ilegales de la Regularización- sí es cierto que el resultado de esa operación puede constituir una aproximación fiable del valor de la inmigración extranjera en España.

Los datos definitivos del Censo de Población de 1991 no han aparecido hasta diciembre de 1994. No consideramos válidos, en lo que se refiere a los extranjeros, los publicados en 1992 en la Muestra Avance del INE por la disparidad observada con los definitivos. En ella se presentaban los principales resultados deducidos del $10 \%$ de los cuestionarios recogidos y con las variables sin depurar. El volumen de población extranjera que arrojaba era de 283.216 personas. Existía al tiempo una cifra de 133.290 personas cuya nacionalidad no constaba. En diciembre de 1994, una vez explotado el $100 \%$ de los cuestionarios, se publica la cifra definitiva de extranjeros: 353.367 personas, esto es, un $25 \%$ más de la cifra de la Muestra Avance.

Los datos estadísticos de la Regularización se desglosan en dos bloques. El primero se refiere a la Regularización de Trabajadores llevada a cabo entre el 10 de junio y el 12 de diciembre de 1991, que ha sido objeto de sucesivos informes desde marzo de 1992 por parte de la Dirección General de Migraciones (DGM), correspondiendo el último a diciembre de 1993. El segundo bloque es el relativo a la Regularización de Familiares, que se prolongó hasta el 10 de marzo de 1992, y cuya información posee la Comisaría General de Documentación de la Dirección General de Policía (DGP).

Este trabajo constituye una aproximación a la inmigración extranjera en España en base a ambas fuentes. Se analizan los contrastes entre la inmigración regular y la irregular y se estudia el valor y perfil general de la población extranjera registrada en España en 1991.

\section{Extranjeros censados}

El Censo de 1991 tiene un valor singular como fuente, ya que investiga un número crecido de variables en relación con la población 
extranjera ${ }^{1}$. Se inscribieron en él 353.367 personas de nacionalidad extranjera, el 0,9 \% de la población censada en España en la fecha.

Esta cifra supone un $27 \%$ más que la de poseedores de tarjeta de residencia que figuran en las estadísticas policiales en fecha comparable: 278.798 a 31 de diciembre de 1990. La estadística anual de extranjeros residentes es fuente primordial en el cálculo de la población regular. La diferencia antes señalada entre censados $\mathrm{y}$ residentes, aunque amplia, está dentro de márgenes admisibles y se explica por la existencia de otras situaciones dentro del marco legal distintas de la de residente (López de Lera, 1991; Ioé, 1992). Consideramos aceptable pensar que la mayoría de los extranjeros inscritos en el Censo se hallaba en situación regular, aunque sin duda quedan incluidos un cierto número de irregulares (G. Lora-Tamayo, 1995). Las características de los censados pueden tomarse a nivel indicativo, en nuestro criterio, como las del colectivo extranjero regular. Los datos sobre permisos de trabajo en fecha comparable parecen corroborarlo: a 31 de diciembre de 1990, el stock era de 85.372 permisos, que podian ascender a 90.000 en la fecha del Censo, si extrapolamos el incremento proporcional operado en el año precedente. La población extranjera ocupada, según el Censo, era de 104.936 personas. La diferencia podría ser imputada, bien a población irregular, bien a los trabajadores comunitarios por cuenta propia que desde 1987 no tendrían obligación de solicitar permiso de trabajo. Comparando ambos bloques de datos -permisos de trabajo y población ocupada-, existen importantes semejanzas: $65 \%$ de varones con permiso, $68 \%$ de varones ocupados; por continentes, $48 \%$ de europeos, frente a $51 \% ; 15 \%$ frente a $16 \%$ de africanos; $25 \%$ frente a $23 \%$ de americanos y $13 \%$ frente a $9 \%$ de asiáticos; por sectores, en el agrario, $4 \%$ frente a $6 \%$; en la industria, $15 \%$ frente a $17 \%$; en la construcción, $7 \%$ frente a $10 \%$, y en los servicios, $74 \%$ frente a $67 \%$.

La población extranjera censada procede mayoritariamente de Europa (cf. figua 1), correspondiendo a los países de la Unión Europea el $50 \%$ y al resto de Europa el $6 \%$. Secundariamente, aunque a

1 Las variables investigadas son sexo, edad, país de origen, país de nacionalidad, estado civil, nivel de instrucción, nivel de actividad, población ocupada por situación profesional, profesión y rama de actividad, país de procedencia de la última migración, fecha de llegada y clase de vivienda. 
gran distancia, destacan como continentes de nacionalidad América del Sur, con el $15 \%$ de los censados, y África, con el $12 \%$. Las contribuciones de Asia, América del Norte, América Central y Oceanía, son muy inferiores. Como apátridas figura un $2 \%$ de los censados.

Por país de nacionalidad, los más representados son los comunitarios, estando a la cabeza el Reino Unido, Alemania, Portugal y Francia, países cuya presencia en España es antigua, figurando en los primeros puestos a lo largo de toda la década (cf. cuadro I). Fuera de los comunitarios, aparecen en los primeros puestos otros también de fuerte tradición en España y unidos a ella por estrechos lazos históricos: así Marruecos, antiguo Protectorado español, o los países latinoamericanos, con Argentina a la cabeza.

En lo que se refiere a su distribución espacial dentro del territorio nacional, Andalucía, Madrid, Cataluña y la Comunidad Valenciana son, por este orden, las comunidades receptoras de la inmigración extranjera más importante (cf. cuadro II). A nivel provincial (cf. figura 2) destaca Madrid, figurando tras ella y a distancia, por este orden, Barcelona, Málaga y Alicante, con un peso de en torno al $12 \%$ cada una de ellas. En el mapa de acogida sobresalen la totalidad de las provincias mediterráneas y las insulares, así como las provincias

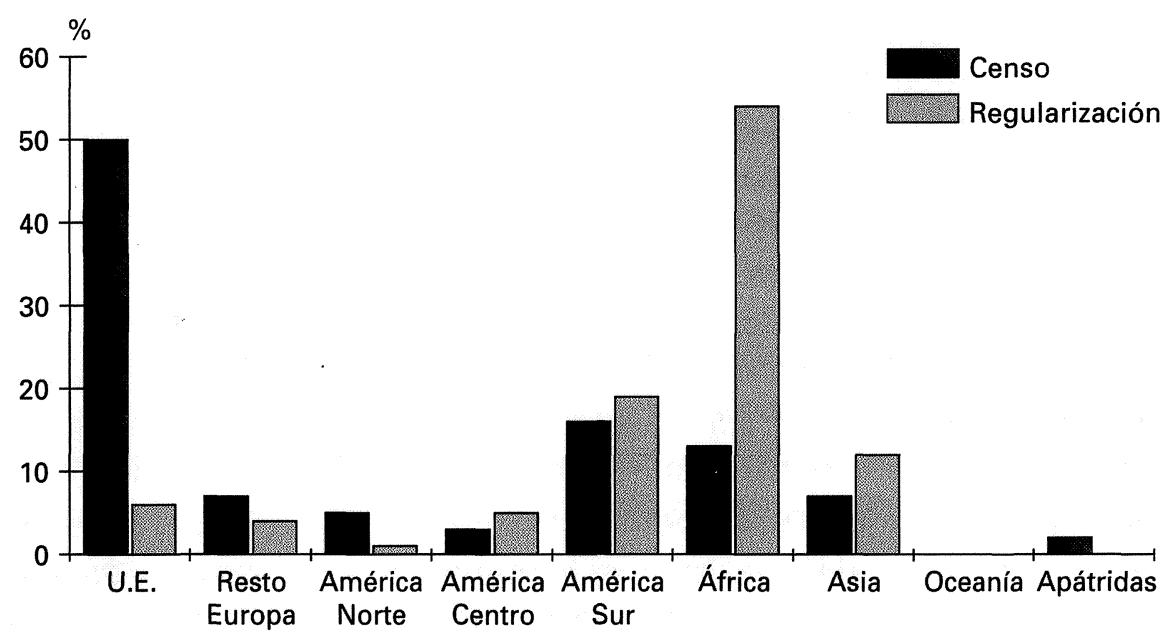

Figura 1.-Continente de nacionalidad de la población extranjera que se inscribió en el Censo y la que acudió a la Regularización (1991) 
NACIONALIDADES DE ORIGEN MÁS REPRESENTADAS ENTRE LOS EXTRANJEROS CENSADOS EN ESPAÑA. 1991

\begin{tabular}{|c|c|c|c|}
\hline & & N. ${ }^{\circ}$ personas & \% Total \\
\hline $1 .^{\circ}$ & Reino Unido . ....................... & 53.554 & 15,2 \\
\hline $2 .^{\circ}$ & Alemania ........................... & 33.952 & 9,6 \\
\hline $3 .^{\circ}$ & Marruecos ............................ & 31.384 & 8,9 \\
\hline $4 .^{\circ}$ & 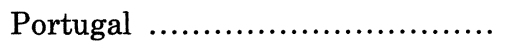 & 27.757 & 7,9 \\
\hline $5 .^{\circ}$ & Francia ................................. & 24.219 & 6,9 \\
\hline $6 .^{\circ}$ & Argentina $\ldots \ldots \ldots \ldots \ldots \ldots \ldots \ldots \ldots \ldots \ldots \ldots$ & 21.250 & 6,0 \\
\hline $7 .^{\circ}$ & Estados Unidos ....................... & 14.413 & 4,1 \\
\hline $8 .^{\circ}$ & 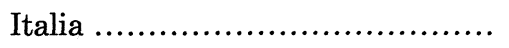 & 11.656 & 3,3 \\
\hline $9 .^{\circ}$ & Países Bajos ....................... & 10.672 & 3,0 \\
\hline $100^{\circ}$ & Venezuela ............................ & 9.458 & 2,7 \\
\hline $11 .^{\circ}$ & Bélgica ............................ & 8.127 & 2,3 \\
\hline $12 .^{\circ}$ & 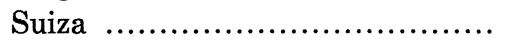 & 6.764 & 1,9 \\
\hline $13 .^{\circ}$ & Chile ............................... & 5.769 & 1,6 \\
\hline $14 .^{\circ}$ & 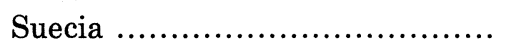 & 5.442 & 1,5 \\
\hline $15 .^{\mathrm{a}}$ & Filipinas ............................ & 5.059 & 1,4 \\
\hline $16 .^{\mathrm{a}}$ & Colombia ........................... & 4.514 & 1,3 \\
\hline $17 .^{\circ}$ & 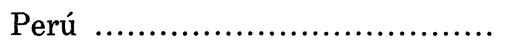 & 4.463 & 1,3 \\
\hline $18 .^{\circ}$ & India $\ldots \ldots \ldots \ldots \ldots \ldots \ldots \ldots \ldots \ldots \ldots \ldots \ldots \ldots \ldots \ldots \ldots \ldots$ & 4.104 & 1,2 \\
\hline $19 .^{\circ}$ & Uruguay ............................... & 3.686 & 1,0 \\
\hline $200^{\circ}$ & Cuba & 3.391 & 1,0 \\
\hline $21 .^{\circ}$ & Méjico .................................... & 3.378 & 1,0 \\
\hline $22 .^{\circ}$ & 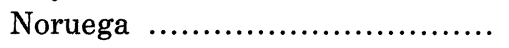 & 3.169 & 0,9 \\
\hline $23 .^{\circ}$ & República Dominicana ............... & 3.161 & 0,9 \\
\hline $24 .^{\circ}$ & 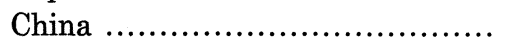 & 2.902 & 0,8 \\
\hline $25 .^{\circ}$ & 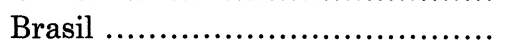 & 2.834 & 0,8 \\
\hline
\end{tabular}

FUENTE: INE. Elaboración propia.

de la cornisa cantábrica -a excepción de Lugo-, las atlánticas y Navarra y Zaragoza.

Madrid y Barcelona, con las ciudades más populosas del país, se presentan como las provincias de atracción más diversificada, con una elevada proporción de ciudadanos comunitarios y latinoamericanos, así como, secundariamente, africanos y asiáticos, destacando dentro de estas comunidades la marroquí y la filipina. La colonia marroquí, concretamente, es la más numerosa de las extranjeras en Barcelona.

$$
-71-
$$




\begin{tabular}{|c|c|c|}
\hline & N. ${ }^{\circ}$ personas & $\%$ Total \\
\hline $\ldots \ldots \ldots \ldots \ldots \ldots \ldots \ldots \ldots \ldots \ldots$ & 61.985 & 17,5 \\
\hline Aragón ....................................... & 3.675 & 1,0 \\
\hline Asturias .................................... & 4.960 & 1,4 \\
\hline 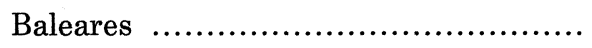 & 17.041 & 4,8 \\
\hline Canarias $. . . . . . . \ldots \ldots \ldots . . .$. & 31.763 & 9,0 \\
\hline 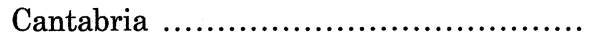 & 2.008 & 0,6 \\
\hline Cast.-La Mancha ......................... & 2.302 & 0,6 \\
\hline 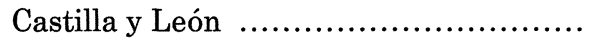 & 10.180 & 2,9 \\
\hline Cataluña $\ldots \ldots \ldots \ldots \ldots \ldots \ldots \ldots \ldots \ldots \ldots \ldots \ldots \ldots \ldots \ldots \ldots$ & 60.659 & 17,2 \\
\hline Com. Valenciana ........................... & 54.213 & 15,3 \\
\hline Extremadura ............................... & 2.503 & 0,7 \\
\hline Galicia .................................... & 17.946 & 5,1 \\
\hline Madrid ........................................ & 61.191 & 17,3 \\
\hline Murcia .................................... & 3.196 & 0,9 \\
\hline Navarra & 2.394 & 0,7 \\
\hline País Vasco ................................. & 9.795 & 2,8 \\
\hline Rioja, La .................................... & 742 & 0,2 \\
\hline Ceuta y Melilla ............................... & 6.814 & 1,9 \\
\hline 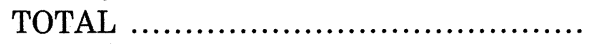 & 353.367 & 100,0 \\
\hline
\end{tabular}

FuENTE: INE. Elaboración propia.

Las provincias mediterráneas y las insulares atraen a ciudadanos comunitarios, relacionados con los asentamientos de jubilados y con los negocios turísticos. Dentro de ello, existe una mayor representación francófona en las provincias catalanas y anglosajona en las andaluzas y las insulares. Fuera de los ciudadanos europeos, en las provincias mediterráneas existe una destacable presencia de la colonia marroquí en Cataluña, Valencia, Murcia y Málaga, en relación, con frecuencia, con el sector agrícola. La presencia marroquí es también destacable en Santa Cruz de Tenerife, por su proximidad geográfica al continente africano. En Canarias, además, se halla muy representada la colonia india, de tradicional presencia en las islas y ligada a la actividad comercial.

En cuanto a Galicia y la cornisa cantábrica existe un predominio de portugueses, por razones de proximidad, y una fuerte atracción de

$$
-72-
$$


algunos países latinoamericanos, sobre todo Venezuela y Argentina, muy en relación con el pasado emigratorio de la región hacia ultramar. León, por su parte, acoge preferentemente a portugueses y caboverdianos, estos últimos relacionados con el trabajo en las minas.

Los extranjeros censados muestran como característica demográfica básica un equilibrio entre los sexos, con una ligera ventaja de las mujeres (51\%). Por edades existe un claro predominio de la población adulta (72\%), siendo el peso de la población infantil -entre $0 \mathrm{y}$ 14 años- del $15 \%$, y el de la población anciana -por encima de los $65-\operatorname{del} 13 \%$.

Los adultos jóvenes suponen el $44 \%$ del total, mientras que los de edades comprendidas entre cuarenta y sesenta y cuatro años, tiene un peso del $28 \%$. En resumen, edad media joven e importancia de la inmigración familiar.

Existen diferencias acusadas entre algunas colonias, imposibles de profundizar en este análisis general. La edad media de la población europea es la mayor, destacando un $18 \%$ de ancianos que contrasta con el $4,5 \%$ entre los africanos o el $6 \%$ entre los sudamericanos y los asiáticos. En el extremo opuesto de la pirámide, los sudamericanos cuentan con la mayor proporción de población infantil $-19 \%$-, frente a asiáticos y africanos, con el $11 \%$ y $12 \%$ respectivamente. Estas dos colonias tienen la mayor proporción de adultos jóvenes y población en edad activa.

En relación con el estado civil, la mitad de la población extranjera es casada; el 40,2\% soltera y el $4,9 \%$ viuda. La proporción de separados y divorciados es muy pequeña. Los solteros están muy representados entre los africanos (53,3\%) y los centro y sudamericanos (48,6 \% en conjunto), superando en ambos casos a los casados; los europeos por su parte reducen a un tercio la proporción de solteros, incrementando la de casados a $56,4 \%$ y la de viudos a $6,1 \%$, un claro reflejo de su estructura por edades.

Una variable de interés singular que investiga el Censo es el nivel de instrucción que, junto con la profesión, permite caracterizar socialmente a las distintas colonias que configuran el conjunto de extranjeros que se halla en España y establecer contrastes entre las 

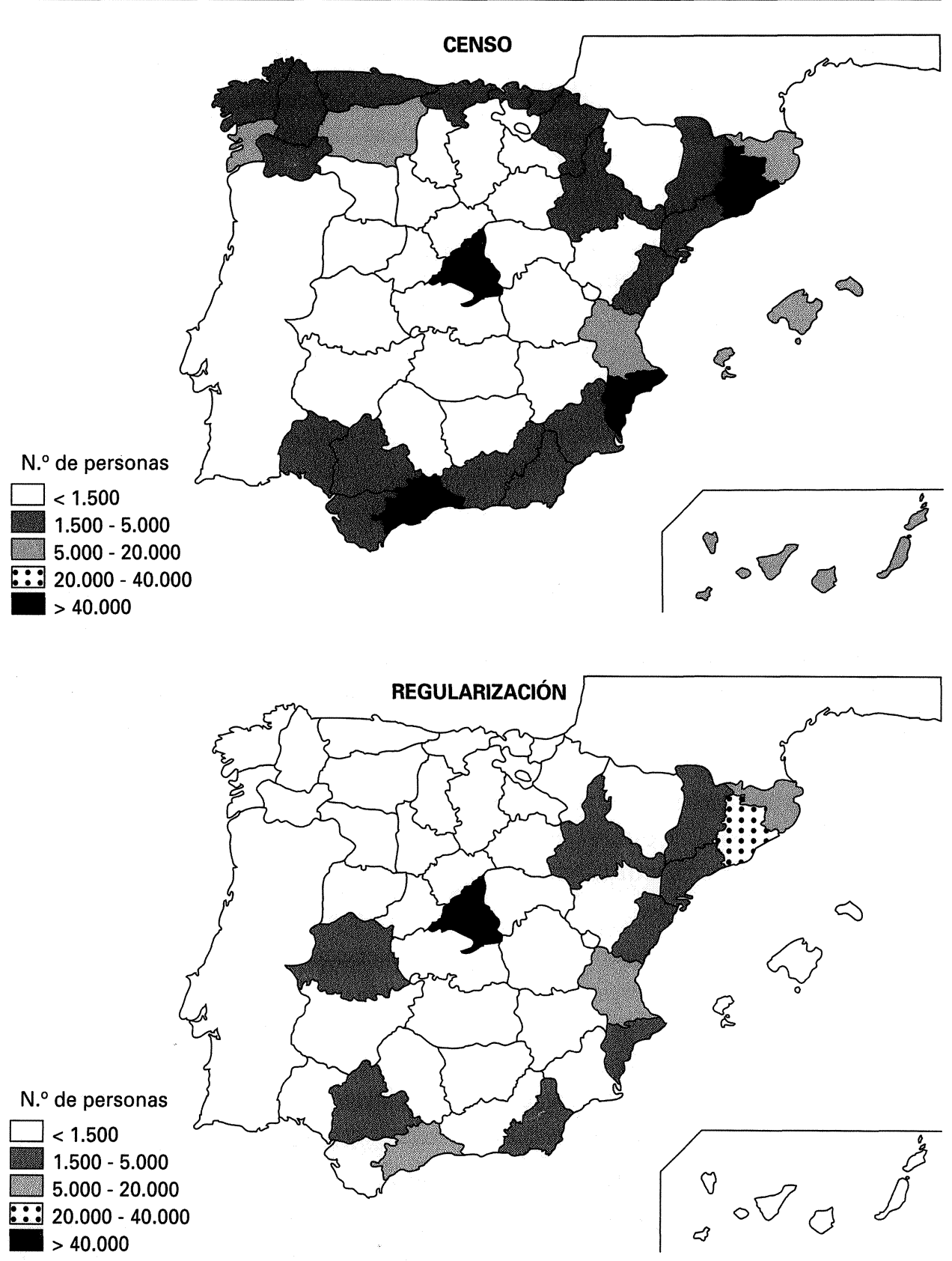

FIGURA 2.-Distribución espacial de la población extranjera inscrita en el Censo y la que acudió a la Regularización (1991) 
mismas. A grandes rasgos, cabe señalar el hecho de que siendo la proporción de analfabetos de un $2,8 \%$ para el conjunto de los extranjeros mayores de diez años, su peso asciende entre los africanos al $11,2 \%$, destacando a nivel nacional los marroquíes con el $12,7 \%$ y los portugueses con el 10,7\%. Ambas colonias se caracterizan por contar con los niveles de instrucción más bajos, constituyendo la población «sin estudios» un $34 \%$ adicional en los primeros y un $24 \%$ en los segundos. El importante grado de analfabetismo funcional que ello refleja sitúa a ambos grupos en posición claramente desventajosa. En el otro extremo de la escala, un $33 \%$ de los norteamericanos, un $24 \%$ de los sudamericanos, un $20 \%$ de los asiáticos y un $17,5 \%$ de los europeos, poseen titulación universitaria de niveles medio o superior.

Son activos el $44 \%$ de los extranjeros mayores de dieciséis años censados. La proporción asciende entre los marroquíes (72\%), en contraste con los comunitarios (51\%). Entre estos últimos, casi la mitad de los inactivos son retirados, jubilados o pensionistas. Mayor interés tienen los datos referidos a la población ocupada -104.936 personas, de las 131.565 activas registradas en el Censo-, que pueden ser comparados con los de la población que acudió a la Regulación de Trabajadores -todos ellos mayores de dieciséis años y con contraro de trabajo-. Un 68 \% son varones, dándose el índice de masculinidad mayor en la colonia africana ( $84 \%$ de varones) y el menor en la centroamericana ( $50 \%$ ), a nivel continental; a escala de país los contrastes son más acusados, mereciendo destacarse las colonias dominicana y filipina, eminentemente femeninas, con un peso del $73 \% \mathrm{y}$ el $66 \%$, respectivamente, de mujeres entre su población ocupada.

Por profesiones, destacan entre los extranjeros censados los profesionales, los trabajadores de la construcción y de la industria y los de la hostelería y servicios, en parecidas proporciones (cf. cuadro III).

Las cifras enmascaran contrastes imposibles de analizar con detalle en este trabajo. Destacamos el elevado porcentaje de profesionales y técnicos entre los norteamericanos (51\%) y sudamericanos (36\%), frente al más bajo de los africanos ( $5 \%$ ). Entre los trabajadores de la hostelería y los servicios sobresalen los asiáticos, un $43 \%$ de los cuales tiene esa ocupación. Un $10 \%$ de los africanos son agri-

$$
-75-
$$


1. Profesionales, técnicos y similares

2. Directivos de organismos públicos y privados...

3. Personal administrativo

4. Agentes comerciales, dependientes y vendedores

5. Trabajadores hostelería y servicios

6. Agricultores, ganaderos, pescadores y similares

7. Trabajadores de la construcción, industria, minería y transporte y peones no especializados .

8. Profesionales de las Fuerzas Armadas TOTAL

$\begin{array}{rr}24.973 & 23,8 \% \\ 5.315 & 5,1 \% \\ 9.903 & 9,4 \% \\ 16.260 & 15,5 \% \\ 21.092 & 20,1 \% \\ 3.961 & 3,8 \% \\ & \\ 22.939 & 21,8 \% \\ 493 & 0,5 \% \\ 104.936 & 100,0\end{array}$

FUENTE: INE. Elaboración propia.

\section{CuAdro IV}

POBLACIÓN EXTRANJERA CENSADA, SEGÚN RAMA DE ACTIVIDAD
A) Agricultura y pesca
$6.030 \quad 5,8 \%$
B) Industria, energía y agua
17.531
$16,7 \%$
C) Construcción
$10.646 \quad 10,1 \%$
D) Comercio
$29.631 \quad 28,2 \%$
E) Otros servicios
41.098
$39,2 \%$
TOTAL
$104.936 \quad 100,0$

FUENTE: INE. Elaboración propia.

cultores o ganaderos y un $44 \%$ son trabajadores de la construcción, industria y minería y peones no especializados.

Por rama de actividad (cf. cuadro IV), la población extranjera ocupada que se inscribió en el Censo se integra fundamentalmente en la rama de otros servicios, que incluye desde las representaciones diplomáticas hasta los servicios domésticos. El Censo no pormenoriza los distintos epígrafes, por lo que su interpretación es difícil. Con los porcentajes más elevados en el grupo figuran América del Norte (67\%), América Central (53\%) y América del Sur (48\%). La rama del comercio, segunda en importancia, tiene su máximo exponente en la población asiática, un $45 \%$ de la cual se adscribe a ella. Por último, de todas las colonias, es la africana la que tiene una mayor preferencia por los sectores de la construcción (21\%) y la agricultura (16\%). 
Las diferencias entre las distintas colonias se resumen básicamente en una mayor tasa de inactividad, edad media más elevada y más alto nivel de instrucción y profesional entre los ciudadanos procedentes de la Unión Europea (excepto Portugal), la EFTA, Norteamericana, Oceanía y países aislados, como por ejemplo Japón, frente a los países subdesarrollados o en vías de desarrollo. El caso de Sudamérica es especial y viene marcado por el importante peso de $\mathrm{Ar}$ gentina en el conjunto: entre los nacionales de este país existe un gran peso de la población infantil, altos niveles de instrucción, con una proporción importante de titulados universitarios de grados medio y superior y abundancia de profesionales y técnicos.

De entre las colonias nacionales de países subdesarrollados o en vías de desarrollo más representadas en España, Marruecos, Portugal y Santo Domingo se sitúan en los niveles socioprofesionales inferiores, con altos índices de analfabetismo funcional, ocupaciones en trabajos de escasa o nula cualificación - peonaje en general, agricultura, construcción y servicios domésticos- e inestabilidad laboral, que se traduce en elevados índices de eventualidad laboral y de paro.

\section{Extranjeros que acudieron a la Regularización}

Las solicitudes presentadas al proceso de Regularización de trabajadores fueron 135.393, de las que una pequeña proporción fueron anuladas por estar duplicadas o tener los solicitantes permiso en vigor (Aragón, R., y Chozas, J., 1992). De las restantes, 5.501 se archivaron por pertenecer a ciudadanos comunitarios, quienes a partir del 1 de enero de 1992 quedaban exentos de la obligatoriedad del permiso de trabajo -si bien con anterioridad a esa fecha se habían resuelto otros expedientes de nacionales de la Unión Europea. Hasta la fecha del último informe estadístico -31 de diciembre de 1993- se habian resuelto 128.128 expedientes de Regularización, de los que resultaron favorables $110.113 \mathrm{y}$ denegatorios $18.015^{2}$.

Debe considerarse la cifra final de extranjeros en situación irregular que acudieron a la Regularización de Trabajadores, en nuestro

2 Las proporciones habrán variado en el último año. 
criterio como de 133.629 personas (128.128 expedientes resueltos +5.501 archivados de comunitarios), no debiéndose tener en cuenta los expedientes anulados (duplicados o con permisos en vigor). La D.G.M. realiza sus estadísticas en base a los expedientes resueltos.

A la Regularización de Familiares, por su parte, acudió un número de 6.777 personas, todas ellas dependientes de los extranjeros que habían regularizado su situación. Se resolvieron favorablemente 5.889 solicitudes.

Sumando la población extranjera que acudió a ambas regularizaciones, la cifra resultante es de 140.406 personas. Todas ellas, con pequeñas excepciones ${ }^{3}$, se hallaban en situación irregular en España en 1991. Se trata, por tanto, del fichero de irregulares más importante del momento. Recordemos que hasta ahora sólo se contaba, en lo que se refiere a datos estadísticos de población extranjera irregular, con los referidos a los extranjeros que acudieron a la Regularización de 1985-86, explotados por A. Izquierdo en numerosas publicaciones. Su volumen era muy inferior ${ }^{4}$ y en la actualidad están desfasados.

Estimamos los datos de la Regularización como representativos del colectivo inmigrante extranjero irregular en España. En lo que se refiere a la cifra global, es imposible conocer su grado de cobertura en relación con la totalidad de los extranjeros ilegales en el momento. Indudablemente hubo extranjeros que no acudieron al proceso por desconocimiento, por miedo o por no reunir los requisitos exigidos. Asimismo, no tuvieron opción a acudir los familiares de los que no se presentaron a la Regularización de Trabajadores, así como los de aquellos que vieron denegada su solicitud.

${ }^{3}$ Los solicitantes de asilo y refugio, en situación regular hasta que se fallaran sus casos, fueron instados por el gobierno a acudir a la Regularización, ante la mayor facilidad de acceso a una situación regular desde ésta que mediante la concesión de la carta de asilo o refugio solicitados, hecho que se produce en un porcentaje mínimo de casos.

${ }_{4}^{4} \mathrm{La}$ anterior Regularización, primera en España, se llevó a cabo entre el 23 de julio de 1985 y el 31 de marzo de 1986 y no tuvo el carácter laboral de la que nos ocupa. Se presentaron a ella 38.181 solicitudes, según datos del Ministerio del Interior (1989), hallándose esta cifra muy distante de las estimaciones de población extranjera en situación irregular que se barajaban en el momento. Posiblemente fue menos representativa del colectivo ilegal que la Regularización del 91. 
En relación con las estimaciones de ilegales que se hacían en torno a esa fecha, la cifra contemplada se acerca sobre todo a una de las calculadas por A. Izquierdo (1992 y 1993 b) -en torno a 132.000 clandestinos en enero de 1990-, hallándose también dentro de las admitidas por el gobierno -entre 90.000 y 170.000 . Se encuentra, sin embargo, distante de otras estimaciones, como la de Ioé -294.000, a diciembre de 1989- o la «cifra estimativa global» de PASS -259.051, a la misma fecha 5 .

La Estadística de Regularización es fuente de interés primordial para el conocimiento de la inmigración irregular en España, no sólo en lo que se refiere al volumen, sino también en lo tocante a sus características. La D.G.M. publica informes del conjunto de la población que acudió al proceso sin desagregar a nivel de país, si bien pueden solicitarse a ese organismo datos a esta escala. En cuanto a las variables analizadas, no son tan numerosas como las del Censo. Algunas de sumo interés para trazar el perfil socioeconómico del grupo, como el nivel de instrucción o la situación laboral, no se investigan. Por ello, el estudio de los irregulares es, en principio, menos completo que el de los censados, aunque no por ello menos interesante.

La procedencia mayoritaria del grupo (cf. figura 1), en contraposición con los extranjeros inscritos en el Censo, es africana: un $54 \%$ de los que acudieron al proceso (Regularización de Trabajadores + Familiares) era nacional de este continente. Secundariamente, casi una cuarta parte procedía de Latinoamérica y un $11 \%$ del continente asiático. Los originarios del llamado «primer mundo» son minoría. La escasa presencia europea y la importancia del continente africano en lo que a la inmigración irregular se refiere, se daban por hecho y se reflejaban en casi todas las estimaciones.

Por países de nacionalidad, de nuevo se observan contrastes en relación con la población censada, figurando a la cabeza Marruecos, seguida a distancia de otros países latinoamericanos, africanos, asiáticos y del Este europeo (cf. cuadro V).

La presencia marroquí es claramente mayoritaria en la inmigración irregular, tal como se suponía: los lazos históricos que unen a

5 Aunque este grupo de trabajo da también, y referida a la misma fecha, otra cifra, 172.682 extranjeros irregulares, considerada como «dato directo». 


\section{Cuadro V}

NACIONALIDADES DE ORIGEN MÁS REPRESENTADAS ENTRE LOS EXTRANJEROS QUE ACUDIERON A LA REGULARIZACIÓN (TRABAJADORES + FAMILIARES) EN ESPAÑA. 1991*

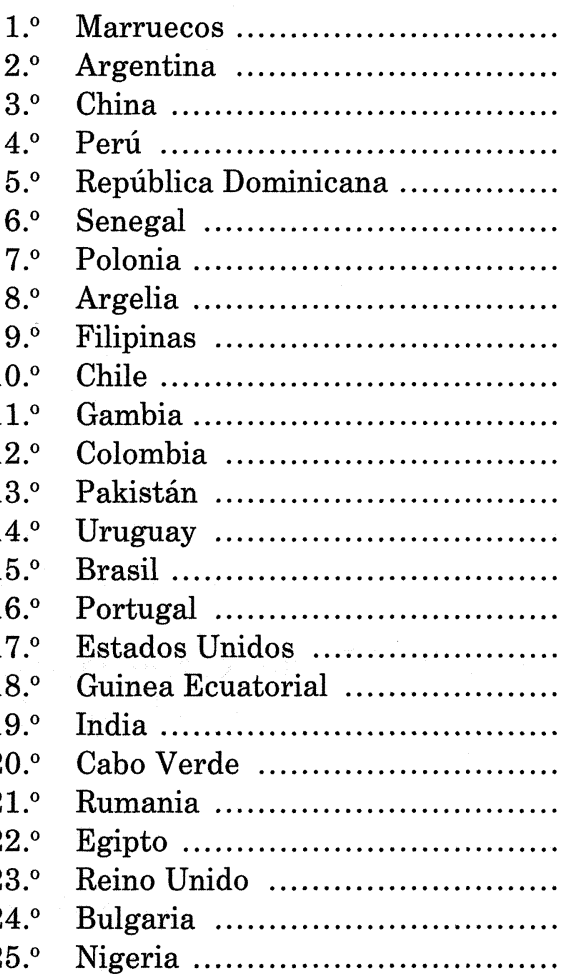

\begin{tabular}{ccc} 
N. $^{\text {o personas }}$ & & \% Total \\
\cline { 1 - 1 } 58.307 & & 43,2 \\
9.144 & & 6,8 \\
7.425 & & 5.5 \\
6.391 & & 4,7 \\
5.911 & & 4,4 \\
4.680 & & 3,5 \\
3.882 & & 2,9 \\
3.757 & & 2,8 \\
2.778 & & 2,1 \\
2.767 & & 2,0 \\
2.760 & & 2,0 \\
2.486 & & 1,8 \\
1.972 & & 1,4 \\
1.792 & & 1,3 \\
1.700 & & 1,3 \\
1.242 & & 0,9 \\
1.116 & & 0,8 \\
919 & & 0,7 \\
760 & 0,6 \\
605 & 0,4 \\
573 & 0,4 \\
536 & 0,4 \\
507 & 0,4 \\
505 & 0,4 \\
503 & 0,4
\end{tabular}

FUENTE: D.G.M. y D.P.G. Elaboración propia.

Marruecos con España, su fuerte presencia en lo que a la inmigración regular se refiere y, sobre todo, la proximidad y fácil acceso hasta el momento, han sido factores decisivos en el continuo incremento de la colonia marroquí irregular en España. Por supuesto, en la base de la corriente está el contraste en cuanto a nivel de vida y desarrollo entre España y Marruecos, las difíciles condiciones económicas, políticas, sociales y ambientales en este último, frente a la imagen de prosperidad de España, y la canalización de la corriente a partir del «efecto llamada». 
Argentina es la segunda colonia en importancia en la inmigración irregular, aunque se sitúa a gran distancia de Marruecos. Su peso entre los inmigrantes regulares es también importante, constituyendo una de las colonias de más fuerte presencia en España.

El carácter de país de inmigración que ha adquirido España en la última década, le viene conferido fundamentalmente por el incremento de la población procedente de países subdesarrollados o en vías de desarrollo, para los que el nivel y formas de vida de España constituyen un reclamo a la hora de seleccionar un destino a su aventura migratoria.

En cuanto al peso de algunos países comunitarios en el conjunto de la inmigración irregular, aun siendo muy pequeño, los datos aportados pueden falsear la realidad, ya que no se han incorporado a ellos los expedientes archivados, como más arriba se indica. En el cuadro presentado aparece Portugal en el puesto dieciséis. Recordemos que el país vecino se hallaba entre los de más peso en lo que a la inmigración regular se refería (cuarto puesto). Entre los expedientes de Regularización de ciudadanos comunitarios resueltos antes del 1 de enero de $1992{ }^{6}$ en número de 2.517 -los correspondientes a ciudadanos portugueses supusieron el $47 \%$-. Extrapolando el dato a las solicitudes archivadas y sumándolo a las resueltas, a Portugal le hubiera podido corresponder un volumen total de 3.782 irregulares, incrementando, por tanto, su importancia de forma notoria dentro de las colonias irregulares y situándose dentro de las diez primeras.

Como se dijo con anterioridad, existe un fuerte contraste entre los países de inmigración irregular y los de inmigración regular. Sin embargo, todas las colonias de fuerte presencia regular tienen una representación, mayor o menor, de inmigración irregular. El hecho se ha señalado antes de ahora, por lo que no vamos a incidir en él. Únicamente recordar cómo en el anterior proceso regularizador, ocurrido en 1985-86, donde las colonias de irregulares más importantes tenían una mayor coincidencia con las de regulares, se explicó la distribución por nacionalidad de aquéllos como «una secreción indo-

${ }^{6}$ No se incluyen las 5.501 solicitudes de ciudadanos comunitarios archivadas, por desconocer a qué nacionalidad corresponden. Los porcentajes se hacen sobre una cifra total de 134.905 personas. 
cumentada de la masa legal» (A. Izquierdo, 1990) o un «efecto masa» (I.E.E., 1990).

Resulta interesante, sin embargo, dentro de esta línea de análisis, estudiar el peso de los irregulares dentro de cada colonia inmigrante en España. Si consideramos a la población censada como regular y la que acudió a la Regularización como irregular, y la suma de ambas como el volumen total de componentes de cada colonia en nuestro país en el momento que nos ocupa, las colonias con una proporción de irregulares mayor serían, por este orden: Senegal, Argelia, China, Polonia, Bulgaria, Pakistán, Nigeria, R. Dominicana, Marruecos, Rumania, Perú, Gambia y Egipto, todas ellas con más del $50 \%$ de irregulares. Se trata sobre todo de población originaria del continente africano, Asia y el Este europeo. Inmigrantes en su mayoría de escasos recursos, con grandes dificultades, por tanto para conseguir su status legal. Ya se han señalado antes de ahora los efectos perversos de la ley de extranjería en el incremento de la inmigración irregular. Los trabajadores extranjeros sin medios económicos tienen más cabida real que legal en el mercado laboral. El volumen, procedencia y perfil -que veremos más adelante- de los que acudieron a la Regularización son un exponente de ello.

La primacía de Cataluña y Madrid como comunidades de acogida de la población extranjera en situación irregular (cf. cuadro VI) es la nota más característica y la que marca mayor diferencia con la población cansada: recordemos que ambas comunidades reunían sólo el $35 \%$ de esta última, en contraste con el $63 \%$ de la que acudió a la Regularización. El resto de las comunidades tienen un peso notablemente inferior, destacando entre ellas Andalucía y la Comunidad Valenciana. Las insulares están poco representadas.

A nivel provincial (cf. figura 2), Madrid se sitúa en cabeza, llegando casi a doblar su representación porcentual en el conjunto nacional, en relación con la población extranjera que se inscribió en el Censo. A continuación, aunque a distancia, figura Barcelona, con el $24,1 \%$. Las restantes provincias tienen valores muy inferiores, mereciendo ser destacadas únicamente Gerona, Murcia, Valencia, Málaga, Alicante, Tarragona, Almería y las Palmas, por este orden, con un peso cada una de entre el 4 y el $2 \%$, dentro del conjunto. El mapa 


\section{Cuadro VI}

COMUNIDAD DE DESTINO DE LA POBLACIÓN EXTRANJERA QUE ACUDIÓ A LA REGULARIZACIÓN (TRABAJADORES + FAMILIARES) EN ESPAÑA. 1991

\begin{tabular}{|c|c|c|}
\hline & N. ${ }^{\circ}$ personas & $\%$ Total \\
\hline$\ldots \ldots \ldots \ldots \ldots \ldots \ldots \ldots \ldots \ldots \ldots$ & 13.252 & 9,8 \\
\hline Aragón & 2.525 & 1,9 \\
\hline 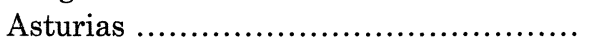 & 629 & 0,5 \\
\hline 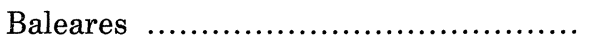 & 3.702 & 2,7 \\
\hline Canarias & 4.156 & 3,1 \\
\hline 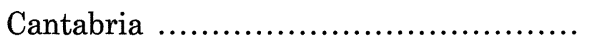 & 598 & 0,4 \\
\hline Cast.-La Mancha ............................. & 2.140 & 1,6 \\
\hline Castilla y León . ............................... & 1.577 & 1,2 \\
\hline 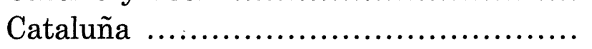 & 42.960 & 31,8 \\
\hline Com. Valenciana ............................. & 9.993 & 7,4 \\
\hline 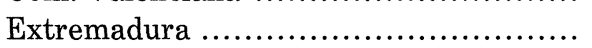 & 1.832 & 1,4 \\
\hline Galicia ....................................... & 1.811 & 1,3 \\
\hline Madrid ....................................... & 41.701 & 30,9 \\
\hline Murcia ........................................... & 5.327 & 3,9 \\
\hline Navarra .................................... & 495 & 0,4 \\
\hline País Vasco ....................................... & 1.595 & 1,2 \\
\hline Riola, La ..................................... & 612 & 0,5 \\
\hline 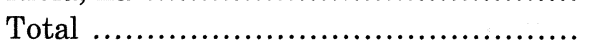 & 134.905 & 100,0 \\
\hline
\end{tabular}

FuENTE: D.G.M. y D.P.G. Elaboración propia *.

* Incluye Ceuta y Melilla.

provincial vuelve a repetir el esquema de la inmigración regular, aunque con un peso muy superior de Madrid y una menor relevancia de las provincias costeras e insulares.

Por colonias, la marroquí supera el $50 \%$ en las tres provincias costeras catalanas, en Málaga y en Murcia, siendo la colonia más representada también en Madrid, Valencia, las Palmas y Alicante. Secundariamente, y a gran distancia, son de destacar los latinoamericanos en Barcelona, los nacionales de Gambia en Gerona y los argelinos en Valencia.

Madrid es, como decimos, el destino más importante de la inmigración irregular. Como ocurría con la inmigración regular, existe una gran diversificación en cuanto al origen por continente de los inmigrantes: África y Latinoamérica contribuyen con más de un tercio 
cada una; Asia con el $14 \%$, la Europa no comunitaria con el $9 \%$, correspondiendo a la Unión Europea, América del Norte, Oceanía y apátridas el $4 \%$ restante ${ }^{7}$. Por países, destaca en Madrid la colonia marroquí, seguida a distancia de la peruana, china, dominicana, polaca, argentina colombiana, filipina y chilena, por este orden ${ }^{8}$.

En resumen, se puede decir que el mapa de destino de la inmigración irregular en España señala los mercados de trabajo más importantes para la población extranjera. El carácter laboral de la Regularización es la explicación del hecho.

En cuanto a las variables demográficas, también el carácter laboral de la Regularización marca el enorme contraste entre el grupo de extranjeros censados y los irregulares. No contamos con datos de los Familiares, que suponen escasamente el $5 \%$ de los extranjeros que acudieron al proceso regularizador en su conjunto. Se analizan aquí los correspondientes a los 128.128 expedientes resueltos -concedidos y denegados-, no computándose los archivados.

Casi las tres cuartas partes de los trabajadores irregulares son varones, siendo el peso de las mujeres únicamente del $26 \%$ del conjunto. En relación con la «población ocupada» del Censo, que es el bloque de datos comparable, existe una mayor proporción de varones entre los irregulares ( $74 \%$ frente a $68 \%$ ) debido, sin duda, al mayor peso de las colonias africanas, con un elevado índice de masculinidad, como ya sabemos.

El perfil de la población irregular es marcadamente masculino y joven. Un $87 \%$ tiene edades comprendidas entre quince y treinta y nueve años y el $13 \%$ restante, entre cuarenta y sesenta y seis años de edad. El peso de la población de más de sesenta y seis años es irrelevante. La distribución por edades es semejante entre los varones y las mujeres, si bien se advierte una mayor juventud en el grupo de los varones. De nuevo la distribución etaria de los africanos, por su fuerte peso en el conjunto, marca la del colectivo irregular. Asimismo, explica el elevado peso de los solteros (un $64 \%$ ) que superan

7 Porcentajes sobre la población que acudió a la Regularización de Trabajadores.

8 Según explotación personal del «Fichero de Regularización del proceso inicial. Madrid», facilitado por la DGM. 
ampliamente a los casados (35\%), siendo mínima la proporción de viudos, divorciados y separados. Todo ello se relaciona con la reducidísima proporción de familiares que acudieron al proceso, hecho que marca un contraste fundamental con el colectivo extranjero regular que se inscribió en el Censo.

Parece indudable que existe una subrepresentación de la población dependiente en situación irregular. Recordemos que al proceso de Familiares no podían acudir más que los dependientes de extranjeros ya regularizados, no teniendo acceso a él los familiares de aquellos que vieron sus solicitudes denegadas. En todos los ámbitos llamó poderosamente la atención el reducido número de familiares que acudió al proceso, muy por debajo de las expectativas de la administración, que calculaba un volumen aproximado de 20.000 (M. Herrera, 1993). Es claro que, aparte los familiares de los trabajadores a quienes se denegó el permiso de regularización, otros dependientes de población regularizada no acudirían por desconocimiento, por ser el plazo insuficiente o por la exigencia de presentar algunos documentos de difícil consecución (DDI, 1993). Terminado el plazo, los familiares no regularizados han podido pasar a formalizar su situación por la vía de la Reagrupación Familiar.

En cuanto a la profesión y rama de actividad, se aprecian también contrastes entre irregulares y censados. Un tercio de los extranjeros que acudieron a la Regularización son trabajadores de la hostelería y los servicios y una cuarta parte, trabajadores de la construcción y de la industria (cf. cuadro VII).

Dentro de estos grandes grupos, los epígrafes con una mayor adscripción son el de encargados y personal del servicio doméstico, con el $18 \%$ del total; trabajadores agrícolas, ganaderos y similares, con el 14,5\%; trabajadores de la construcción, con el $13 \%$; cocineros, camareros y similares, con el 10,5\%, y comerciantes, vendedores y similares, con el $8 \%$, sumando entre los cinco dos tercios del total de los trabajadores. El contraste entre las profesiones de mayor cualificación, con la mayor adscripción de censados, y las de menor cualificación, con mayor adscripción de irregulares, es claro. 


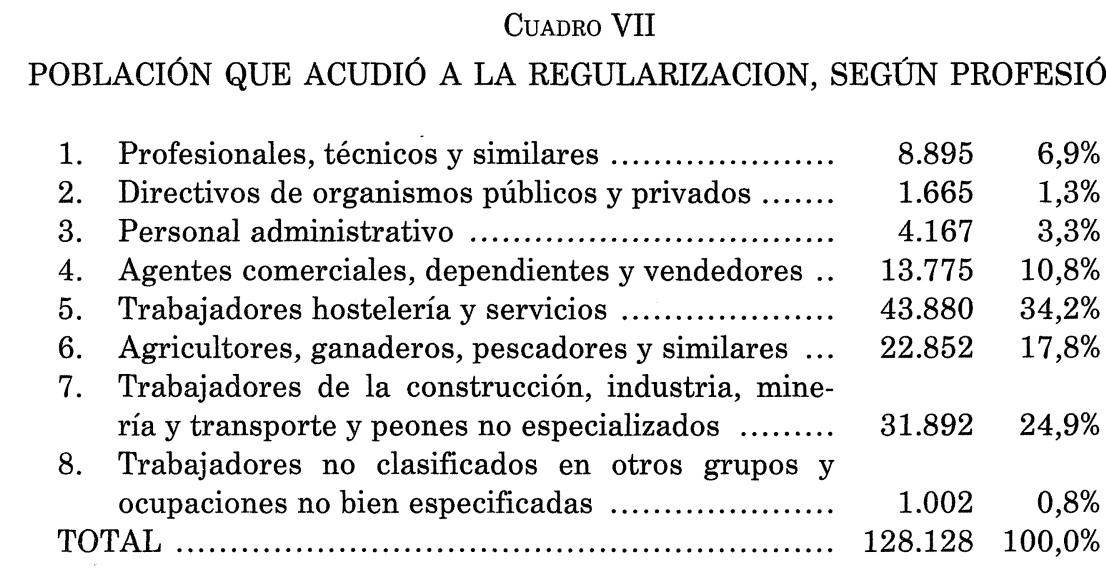

FuENTE: D.G.M. Elaboración propia.

En cuanto a las ramas de actividad, destaca entre los irregulares «otros servicios», seguida del comercio (cf.' cuadro VIII). La mayor parte de los trabajadores irregulares engrosan el servicio doméstico ( $20 \%$ del total); la contrucción ( $16 \%$ ); producción agrícola (14\%); hostelería (12\%), y servicios prestados a las empresas (8\%).

\section{Extranjeros en España en 1991: Conclusión}

Aunque es imposible medir con absoluto rigor el volumen de población extranjera en España en la fecha de referencia, consideramos la cifra de medio millón de personas como la más próxima a la realidad, tomando como base del cálculo las dos fuentes analizadas en este trabajo. Una cifra semejante se obtiene poniendo en relación el volumen de extranjeros residentes a diciembre de 1990 de las Estadísticas policiales, con la cifra de irregulares de las Estadísticas de Regularización ${ }^{9}$.

9 Según la siguiente operación: 276.796 (extranjeros con tarjeta de residencia) + un $20-30 \%$ de esa cifra (extranjeros en otra situación regular distinta de la de residencia) +140.406 (personas registradas en la Regularización) = entre 472.561 y 500.240 personas. Por otra parte, la suma de los censados con los que acudieron a la Regularización da un resultado de 493.773 extranjeros. 
POBLACIÓN QUE ACUDIÓ A LA REGULARIZACION, SEGÚN RAMA DE ACTIVIDAD
A) Agricultura y pesca
$20.675 \quad 16,1 \%$
B) Industria, energía y agua .......................... 9.438
C) Construcción ....................................... 20.533
D) Comercio ....................................... 31.747

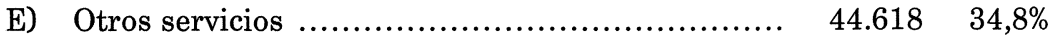

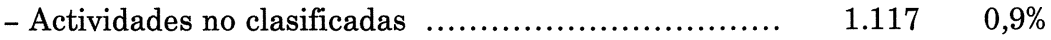

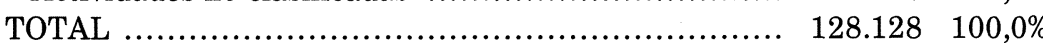

FuENTE: D.G.M. Elaboración propia.

El Censo y las Estadísticas de Regularización, aparte de poner de relieve la sobreestimación del colectivo extranjero en nuestro país en los últimos años, son útiles a la hora de trazar el perfil de las colonias que viven en él.

En principio, y con ánimo de simplificar, podríamos hablar de las dos caras de la presencia extranjera en España: ciudadanos del «primer mundo» comparten nuestro solar, a partes iguales, con los del «tercer mundo» y Portugal. En una mirada más profunda, sin embargo, se descubren diferencias nítidas dentro de ese gran bloque que conforman los países subdesarrollados y en vías de desarrollo.

Latinoamérica, por ejemplo, adopta «presencias» distintas, pudiéndose diferenciar dos tipos de flujos hacia España: uno de inmigrantes cualificados -representado por Méjico o Argentina- y otro de inmigrantes sin cualificación alguna -cuyo ejemplo más destacado sería Santo Domingo-. Argentina, con la colonia más numerosa, es un exponente de la inmigración procedente del Cono Sur y configura en España una colonia urbana, familiar, joven y activa, con abundancia de profesionales y técnicos. Mayor status tiene la colonia mejicana, compuesta por titulados universitarios en una tercera parte y donde la mitad de la población ocupada son profesionales y técnicos. Ambos grupos nacionales contrastan con la colonia dominicana, de reciente presencia y cuyas características básicas son el desarraigo familiar, el perfil femenino, la edad selectiva y el bajo nivel sociolaboral: prototipo de inmigración económica. También la inmigración cubana o peruana tiene perfiles contrastados. Descender a cada colonia desde 
el mirador privilegiado de las dos fuentes estudiadas es tarea de sumo interés.

En Asia tienen personalidad propia colonias como la india, de antigua presencia, familiar y bien implantada; o la filipina, joven, femenina y eminentemente activa. Contrastan con colonias como la japonesa, un grupo de élite entre los extranjeros, constituido por familias enteras, cuyos cabezas son profesionales y directivos.

La presencia europea en España es mayoritariamente comunitaria y, por tanto, excepto en el caso de Portugal, exponente del primer mundo. Dentro del continente, Portugal y los países del Este pueden incluirse en las corrientes de inmigración económica procedentes de países en vías de desarrollo. Aún estas dos colonias son muy contrastadas: los portugueses, con bajo nivel de instrucción y sociolaboral globalmente, muestran una gran heterogeneidad en función de su antigüedad y localización dentro del territorio nacional, como ya ha sido puesto de relieve (L. López Trigal, 1994). La colonia polaca, por su parte, tiene un enorme interés por sus contrastes internos y su carácter de inmigración económica, a pesar de su elevado nivel de instrucción.

África es el continente que en mayor medida genera flujos de inmigrantes económicos hacia nuestro país, personas que vienen en busca de un futuro mejor, que viven de su trabajo por cuenta propia o ajena, enviando sus ahorros a su país de origen y que ocupan los puestos menos cualificados. Dentro de África también se pueden singularizar colonias, como la nigeriana o la egipcia, cuyos componentes, hombres sobre todo, tienen altos niveles de instrucción. Sin embargo, la colonia marroquí, por su volumen, es la más representativa de la presencia africana en España: el grupo social en mayor desventaja por sus características intrínsecas -alto grado de analfabetismo funcional, desarraigo familiar, bajo nivel sociolaboral y diferencia de raza, lengua, religión y cultura- y también por el marco administrativo y legal en el que se desenvuelve en nuestro país.

Las colonias de inmigración económica -marroquí, dominicana, portuguesa o polaca, entre otras- son mayoría entre los extranjeros en situación irregular, constituyen la nueva clase obrera de nuestra sociedad, con cabida en el mercado laboral, como la propia adminis- 
tración reconoce ${ }^{10}$, pero con problemas de carácter legal, como más arriba se indicó.

Dentro del marco del llamado "primer mundo» se advierten también presencias distintas: colonias constituidas sobre todo por rentistas y jubilados -la inglesa, alemana, suiza- y colonias activas -italiana, estadounidense-, que acompañan al capital extranjero y cuyos componentes se hallan en situación sociolaboral privilegiada, siendo en un alto porcentaje profesionales y técnicos. Unos y otros tienen mayor antigüedad en nuestro país que las colonias que hemos denominado de inmigración económica. De alguna manera, extranjeros de élite e inmigrantes económicos configuran la realidad dual de España en el mundo de las migraciones. Se puede decir que España es hoy en día «Norte» para el «Sur», mientras continúa siendo «Sur» para el «Norte».

La «política activa de inmigración», desarrollada por el gobierno a partir de 1991, mantiene las puertas abiertas a los países ricos -en 1992 establece la libre circulación de trabajadores con los comunitarios-, mientras canaliza los flujos procedentes de los países subdesarrollados y en vías de desarrollo -a través del contingente de autorizaciones de trabajo y residencia y la reagrupación familiar-, aunque también dentro de ellos establezca preferencias claras.

El problema de la inmigración irregular no se ha resuelto con la Regularización de 1991 y la imposición de visado a numerosos países. De momento, el proceso dejó atrás un cierto número de personas sin legalizar su situación: los que no se presentaron, los que vieron denegada su solicitud y los familiares de todos ellos. A ellos se han unido los que no han podido renovar su permiso en años sucesivos, así como los que hayan entrado o vayan a entrar al país por cauces no legales.

10 «... a pesar de la existencia de altas tasas de desempleo, la configuración y frag mentación del mercado de trabajo provocará que existan "nichos laborales", que, por su precariedad, informalidad o naturaleza de la prestación, serán rechazados por los trabajadores nacionales $\mathrm{y}$, en cambio, resultarán atrayentes para nuevos inmigrantes. $\mathrm{Su}$ presencia, en un mercado catacterizado por rigideces estructurales, introduce un factor de flexibilidad y representa una aportación, desde el punto de vista productivo, nada despreciable» («Plan de Integración de los Inmigrantes», DGM, 1995). 
Una cierta esperanza se abre en estos momentos ante la reforma del reglamento de extranjería, con la inminente puesta en marcha, entre otras medidas, del estatuto de residente permanente, consistente en la concesión al inmigrante, tras un plazo razonable de residencia en España, de un permiso de trabajo y/o residencia indefinida. Ello acabaría con la inseguridad e inestabilidad que lleva a tantas personas a no poder renovar sus «papeles» y pasar a la ilegalidad.

\section{BIBLIOGRAFÍA}

Adroher Biosca, S., y Gortazar Rotaeche, C. J. (1994): «Marco jurídico de la inmigración y el asilo en España», Cuadernos de Formación, n. 5. Delegación Diocesana de Migraciones-A.S.T.I.

Aragón Bombín, R. (1991): «Hacia una política activa de inmigración», Economía y Sociología del Trabajo, n. 11, pp. 97-106.

AragónBombín, R., y Chozas Pedrero, J. (1993): «La Regularización de Inmigrantes durante 1991-1992». Ministerio de Trabajo y Seguridad Social.

Cáritas (1995): Entre Culturas, Boletín del Programa de Inmigrantes de Cáritas Española, n. 14, febrero 1995.

Colectivo IOE (1987): «Los Inmigrantes en España», Documentación Social, n. 66, eneromarzo.

- (1989): «España, frontera sur de Europa», Documentación Social, n. 77, pp. 101-112, octubre-diciembre 89.

- (1993): «Rasgos generales y perfil sociodemográfico de las principales colonias». En GIMÉnez ROMERo, C. (Coord.) (1993): «Inmigrantes extranjeros en Madrid», t. I, pp. 137-418.

Comunicación del Gobierno al Congresos de los Diputados (1990): «Situación de los extranjeros en España. Líneas básicas de la política española de extranjería».

Delegación Diocesana de Inmigrantes (1993): «El derecho a la reagrupación familiar en España», Cuadernos de Formación, n. 2, D.D.I.-A.S.T.I.

Dirección General del Instituto Español de Emigración (1990): «La inmigración en España. Panorama de una década: 1980-89». Ministerio de Trabajo y Seguridad Social.

Dirección General de Migraciones: «Regulación de Inmigrantes 1991». Informe a 10 de marzo de 1992.

Dirección General de Migraciones (1993): «Informe Estadístico de Regularización hasta el 31 de diciembre de 1993». Ministerio de Asuntos Sociales.

- (1993): «Fichero de Regularización del proceso inicial. Madrid». Actualización: 1 de diciembre de 1993. Soporte magnético.

- (1992, 1993, y 1994): «Anuario de Migraciones, 1992». Idem., 1993, 1994. Ministerio de Trabajo y Seguridad Social.

- (1995): «Plan para la Integración Social de los Inmigrantes». Ministerio de Asuntos Sociales.

Dirección General de Policta (1993): «Regularización de familiares de trabajadores extranjeros». Comisaría de Documentación. 
FUNDACIÓN CIPIE (1993): «Programa de sensibilización de opinión pública sobre inmigración y desarrollo. Análisis de la prensa española sobre inmigración». Trimestral.

García Bilbao, P. A. (1993): «Sobre la Comunidad Europea y su política de inmigración», Sociedad y Utopia, 1/1993, pp. 101-116.

GozÁlvez Pérez, V. (1989): «El reciente incremento de la población extranjera en España y su incidencia laboral». Ponencia presentada al Seminario Internacional «L'offre de travail, chômage et migrations: situation actuelle et perspectives pour l'Ouest du Bassin Mediterranéen», Positano (Italia), 22-24 octubre 1989.

HerRera, M. (1993): «Inmigración, xenofobia y racismo en España». Sal Tarrae, enero 1993, pp. 55-71.

I.N.E. (1992): «Censos de Población y Viviendas, 1991. Muestra Avance. Principales Resultados», Madrid.

- (1994): «Censo de Población de 1991. Tomo I. Resultados Nacionales», Madrid.

IzQUIERDo Escribano, A. (1991): «La inmigración ilegal en España. Análisis de la operación extraordinaria de Regularización de 1985-86», Economía y Sociología del Trabajo, n. 11, pp. 18-38. Ministerio de Trabajo y Seguridad Social.

- (1992): «La inmigración en España, 1980-1990». Ministerio de Trabajo y Seguridad Social. Col. Informes, 17.

- (1993): «Política e inmigración en la España de 1992». En AA.VV. «Inmigración, pluralismo y tolerancia», Ed. Popular, Col. Jóvenes contra la intolerancia, Madrid, pp. 87-124.

- (1993): «La política de inmigración en España: Costes y beneficios de la integración en la Comunidad Europea», Sociedad y Utopia, n. 1, 1993, pp. 117-125.

Ley Organica 7/1985, de 1 de julio, sobre Derechos y Libertades de los Extranjeros en España.

LÓPEZ DE LERA, D. (1991): «Análisis de la estadística sobre población extranjera». Terceras Jornadas de la Población Española. Diputación Provincial de Málaga, pp. 95-107.

LOPEZ GARCíA, B. (1993): «La inmigración marroquí en España: la relación entre las geografías de origen y destino». Política y sociedad, 12, 1993, pp. 79-88.

LÓPEZ TRIGAL, L. (Dir.) (1994): «La migración de portugueses en España», Universidad de León.

Lora-TAmayo D’Ocon, G. y A. (1991): «Aproximación al estudio de la inmigración extranjera en España y la Comunidad de Madrid. Primera recopilación de fuentes y bibliografía». III Jornadas de la Población Española. Diputación Provincial de Málaga, pp. 117-125.

LORA-TAMAYO D’OCon, G. (1994): «Valor de la inmigración extranjera en España», Espacio, Tiempo y Forma, serie VI, n. 7, pp. 83-134.

Lora-Tamayo D'Ocon, G. (1995): «Características de la población extranjera en España. Censo de 1991», Cuadernos de Formación, n. 6. Delegación Diocesana de Inmigrantes. A.S.T.I.

Marcos SANZ, R. DE, y Rojo AlCALDE, J. (1991): «Trabajadores Extranjeros en España», Economia y Sociología del Trabajo, 11 de marzo de 1991, pp. 8-17. Ministerio de Trabajo y Seguridad Social.

MiNISTERIO DEL INTERIOR (1989): «Cuadros estadísticos de Regularizaciones 1985-86». En «Memoria 1989», pp. 126-131.

Muñoz Pérez, F., e Izquierdo Escribano, A. (1989): «L'Espagne, pays d'inmigration», Population, n. 2, pp. 257-289. 
OChOA DE Michelena, C. (1993): «La inmigración hacia España de los naturales de países terceros a la CEE: un nuevo fenómeno», Politica y Sociedad, n. 12, 1993, pp. 97-120.

PASS (1990): «Mapa de trabajadores extranjeros en situación irregular en España». Dirección General del I.E.E.

Pumares Fernández, P. (1993): «Problemática de la inmigración marroquí en España», Política y Sociedad, n. 12 (1993), pp. 139-147.

Villegas Martinez, J. (1991): «El Acuerdo de Schengen y la libre circulación de personas en la Comunidad Económica Europea». Boletín de Documentación, n. 125, julioseptiembre 1991. Secretaría General Técnica. Ministerio del Interior, pp. 39-52.

RESUMEN: Extranjeros en España en 1991. En 1991 coinciden dos fuentes de singular importancia para el conocimiento del fenómeno inmigratorio en España: un censo de población y los datos estadísticos de la Regularización de trabajadores extranjeros y de sus familiares, llevada a cabo ese mismo año. En este trabajo se analizan los contrastes entre los extranjeros censados y los que acudieron a la Regularización y se realiza una estimación del volumen y características de la población de nacionalidad extranjera presente en España en esa fecha.

Palabras Clave: España. Inmigración. Extranjeros. Censo. Regularización.

ABSTRACT: Foreigners in Spain en 1991. In 1991 two sources of remarkable importance for the knowlwdge of the Spanish inmigrational phenomenon coincided: the Population Census and the Regularization for alien workers and their families. This paper analyzes on the one hand the contrasts between the two sources, and on the other the total foreign population existing at that time in Spain and its characteristics.

KEY woRDS: Spain. Immigration. Aliens. Population Census. Regularization.

RÉSUMÉ: Étrangers en Espagne en 1991. A 1991 il y a una coïncidence de deux sources de particulière importance pour la connaissance du phénomène inmigratoire en Espagne: le Recensement de Population et les donneès statistiques de la Regularisation des Travailleurs ètrangers et de ses familles qui eut lieu la même année. Dans ce travail on analyse les contrastes entre les étrangers recensés et ceux qui ont eu recours à la Regularisation. On a fait aussi une estimation du volume de population de nationalité étrangère en Espagne à cette date-là. tion.

MoTS CLÉ: Espagne. Inmigration. Étrangers. Recensement de Population. Regularisa- 